
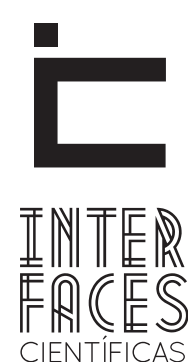

HUMANAS E SOCIAIS

ISSN IMPRESSO 2316-3348

E-ISSN 2316-3801

DOI - 10.17564/2316-3801.2018v7n1p71-82

\title{
JUVENTUDES, VIOLÊNCIAS E INTERSECCIONALIDADES NO BRASIL: REFLEXÕES A PARTIR DO ESTATUTO DA JUVENTUDE
}

\author{
YOUTH, VIOLENCE AND INTERSECTIONALITIES IN BRAZIL: REFLECTIONS ALONG THE ESTATUTO DA JUVENTUDE
}

JUVENTUD, VIOLENCIAS Y INTERSECCIONALIDAD EN BRASIL: REFLEXIÓN SOBRE ESTATUTO DA JUVENTUDE

\section{RESUMO}

Este artigo, por meio da temática da juventude, busca analisar as interseccionalidades entre gênero, sexualidade, raça, etnia e classe, tendo como norte a relação entre violências, políticas públicas e garantia de direitos humanos no Brasil. Desse modo, utilizou como instrumento de dados o Estatuto da Juventude, promulgado mediante a Lei $n^{0} 12.852 / 2013$. Considera-se que a interface entre as dimensões racial, étnica, de gênero, de sexualidade e de classe, perante um Estado hegemônico, são fatores estruturantes de vitimização juvenil e atuam como marcadores de desigualdade social. Diante dessa realidade, o Estatuto da Juventude, enquanto legislação que institui políticas públicas para garantia de direitos humanos, ainda não impactou o acesso e a garantia de direitos da juventude em maior condição de vulnerabilidade social. Com o cenário político atual, esta problemática tem se acentuado no Brasil, que vive um período de retrocessos antidemocráticos, acompanhados de discursos de ódio, que fomentam violências interseccionais. Como reflexo de toda opressão social do próprio sistema onde estão inseridos, os jovens são alvo de altos índices de violência e evidenciam sua condição de segregação e invisibilidade.

\section{PALAVRAS-CHAVE}

Juventudes. Violências. Interseccionalidades. Estatuto da Juventude. 


\section{ABSTRACT}

This article, through the theme of youth, seeks to analyze the intersectionalities between gender, sexuality, race, ethnicity and class, based on the relationship between violence, public policies and guarantee of human rights in Brazil. In this way, it used as a data instrument the Youth Statute, promulgated through Law 12,852 / 2013. It is considered that the interface between racial, ethnic, gender, sexuality and class, brought before the hegemonic State, are structuring factors of juvenile victimization and that act the markers of social inequality. In view of this reality, the Statute of Youth, legislation that establishes public policies to guarantee human rights, has not yet impacted the access and guarantee of the rights of young people, especially those in greater condition of social vulnerability. With the current political scenario, this problem has intensified in Brazil, which lives in a period of anti-democratic setbacks, accompanied by discourses of hatred, which foment intersectional violence. As a reflection of all the social oppression of the system where they are involved, young people are targeted high rates of violence and evidencing their condition of segregation and invisibility.

\section{KEYWORDS}

Youth. Violence. Intersectionalities. Estatuto da Juventude.

\section{RESUMEN}

Este artículo, a través del tema de la juventud, busca analizar las interseccionalidad entre género, sexualidad, raza, etnia y clase, teniendo como norte las relaciones entre violencias, políticas públicas y en garantía de los derechos humanos en Brasil. Por lo tanto, utilizó como instrumentos de datos el Estatuto de la Juventud, promulgado mediante la Ley $n^{\circ} 12.852 / 2013$. Considerando que la interfaz entre las dimensiones raciales, étnicas, de género, de sexualidad y de clase, ante un Estado hegemónico, son elementos estructurales de victimización juvenil y que actúan como marcadores de la desigualdad social. Delante de esta realidad, el Estatuto da Juventude, mientras la legislación que instituye las políticas públicas para la garantía de los derechos humanos, aún no ha impactado el acceso y la garan- tía de los derechos de la juventud, especialmente aquellos en mayor vulnerabilidad social. Con el actual escenario político, este problema viene acentuándose en Brasil, que vive un período de retrocesos antidemocráticos, acompañándose con discursos de odio, que fomentan violencias interseccionales. Así, con el reflejo de toda la opresión social del propio sistema donde están inseridos, los jóvenes son blancos de alto índices de violencia y evidencia sus condiciones de segregación e invisibilidad.

\section{PALABRAS CLAVES}

Juventud. Violencias. interseccionalidad. Estatuto da Juventude. 


\section{INTRODUÇÃO}

Este artigo versa sobre a temática da juventude, tendo como objetivo refletir de maneira crítica sobre a implementação de políticas públicas e a garantia de direitos humanos no Brasil, por meio de uma abordagem interseccional sobre as violências motivadas por gênero, sexualidade, raça, etnia e classe que acometem a população jovem. Para embasar o debate frente a essa problemática, apresenta uma análise documental, utilizando como instrumento de dados o Estatuto da Juventude, o qual foi sancionado através da Lei n012.852, de 5 de agosto de 2013 (BRASIL, 2013a).

A legislação supracitada, dispondo sobre os direitos dos jovens, por meio de princípios e diretrizes para políticas públicas, sana a lacuna do ciclo de leis geracionais, que caminham na mesma perspectiva do Estatuto da Criança e do Adolescente (BRASIL, 1990) e do Estatuto do Idoso (BRASIL, 2003). O Brasil foi o primeiro país da América Latina a adequar a legislação aos princípios da Convenção das Nações Unidas sobre os Direitos da Criança, que aconteceu em novembro de 1989 e foi ratificada pelo país em setembro de 1990.

Antes disso, em julho daquele ano, nasceu o Estatuto da Criança e do Adolescente (ECA), instaurado pela Lei 8.069/90. O Estatuto reforçou alguns preceitos já determinados pela Constituição de 1988, como a proteção integral de crianças e adolescentes e a prioridade na formulação de políticas públicas, na destinação de recursos da União e no atendimento de serviços públicos.

A Lei do ECA considera crianças os que têm até 12 anos de idade e adolescentes aqueles que têm entre 12 e 18 anos. A partir disso, estabelece que é dever do Estado, da família e da sociedade garantir o direito de crianças e adolescentes à liberdade, à dignidade, à convivência familiar e comunitária, à saúde, à educação, à cultura, ao esporte, ao lazer, à profissionalização e à proteção do trabalho. Além disso, o ECA prevê a proteção contra qualquer forma de exploração, discriminação, violência e opressão, contemplando todas as crianças e adolescentes do Brasil (BRASIL, 1990).
Nesse sentido, cabe destacar um ponto inicial, no que compete à escolha pelo Estatuto da Juventude como base desta análise. Observando os dois primeiros parágrafos, do art. $1^{\circ}$ da Lei em tela, lê-se:

\begin{abstract}
$\S 1^{\circ}$ Para os efeitos desta Lei, são consideradas jovens as pessoas com idade entre 15 (quinze) e 29 (vinte e nove) anos de idade.

$\S 2^{\circ}$ Aos adolescentes com idade entre 15 (quinze) e 18 (dezoito) anos aplica-se a Lei no 8.069, de 13 de julho de 1990 - Estatuto da Criança e do Adolescente, e, excepcionalmente, este Estatuto, quando não conflitar com as normas de proteção integral do adolescente (BRASIL, 2013a).
\end{abstract}

Ou seja, o Estatuto da Juventude, é aplicado de maneira concomitante ao ECA, pelo fato de abranger uma parte da população de uma mesma faixa etária. Desta forma, vigorando a partir do ano de 2014, ele tem como objetivo promover a proteção, partindo do conceito de juventude explicitado pela Organização das Nações Unidas (ONU) ${ }^{1}$, preenchendo uma lacuna etária, até então não contemplada pelo ECA. Assim, a juventude não é mais compreendida a partir de uma passagem da infância para a vida adulta, mas "como um percurso para emancipação social e como um tempo próprio para viver a vida juvenil" (BRASIL, 2011, p. 2).

Observou-se que o Estatuto da Juventude abrange vários fatores que o Estatuto da Criança e do Adolescente não provêm. As razões para isso podem estar associadas a um teor histórico e temporal, de maneira que, por ter sido promulgado na década de 1990, muitos temas ainda não tinham a amplitude de um debate mais aprofundado quanto em 2013, período no qual o Estatuto da Juventude foi ratificado.

Então, como é o exemplo das temáticas que tem eixo central deste artigo (gênero, sexualidade, raça, etnia e classe), por não estarem naquele momento consolidadas no campo legal como demandas legítimas por direitos, também não são destacadas no formato

1 A ONU indicou as idades de 15 a 24 anos como um conceito médio de juventude, no entanto, as Nações Unidas admitiam que cada país poderia adotar uma faixa jovem diferenciada, de modo que com o Estatuto da Juventude, esse recorte etário é ampliado até os 29 anos, buscando efetivar o pleno direito da juventude no Brasil (AMORIM, 2011). 
da Lei. Assim, quando se busca a palavra "gênero" no corpo do texto do ECA, por exemplo, é um vocábulo completamente inexistente. 0 mesmo ocorre com a palavra "classe" e de modo semelhante, a palavra "raça" é encontrada apenas uma vez, no parágrafo único do artigo $3^{\circ}$. Ou seja, esses temas, na década de 1990, ainda estavam desabrochando muito timidamente dentro das estruturas de Estado, mesmo que já estavam em efervescência no campo dos movimentos sociais.

Desse modo, se torna inviável analisar numa abordagem interseccional as nuances envoltas na discussão sobre gênero, sexualidade, raça, etnia e classe, que devem ser incorporadas por políticas públicas de direitos humanos, em um documento onde se quer foram mencionadas tais problemáticas, como é o caso do ECA (BRASIL, 1990). Embora este já tenha sofrido várias alterações, é somente no Estatuto da Juventude, instituído em 2013, onde aparece um diálogo sobre essas questões voltadas para a juventude. Pautado nisso, deu-se a escolha por analisar esta legislação em específico.

O Estatuto abordado, apontando uma gama de direitos que devem ser garantidos, coloca ao Estado brasileiro a obrigação de efetivação de políticas públicas dirigidas a jovens, independente do governo vigente (BRASIL, 2013a). Ocupando um papel de supremacia constitucional, haja vista que é concretizado em formato de Lei e incorporado na Constituição Federal (BRASIL, 1988), o documento em tese pauta todas as políticas, programas e projetos que tenham conexão com a população juvenil, determinando assim, que o conjunto de ações posteriores a sua implantação, deve estar em concordância com seus termos.

Essas determinações, além de estarem embutidas na Constituição Federal, também estão atreladas a um conjunto de normatizações internacionais de direitos humanos, que somadas tem o objetivo de suprir mazelas e demandas sociais. Pode-se dizer que há um amplo leque de fatores que compõe o conjunto de direitos humanos, que emanam em resposta as diversidades socioculturais carregadas de desigualdade, as quais são pioneiras na história do Brasil (SILVEIRA et al., 2007).
Em contrapartida de uma bagagem de injustiças, que colocam gênero, sexualidade, raça, etnia e classe como marcadores sociais de desigualdade, ressaltam-se as lutas sociais para a aplicação de direitos humanos de forma igualitária, que dentre tantas reivindicações, resultaram diferentes avanços, inclusive dentro do campo da legalidade do Estado e das práticas normativas do Direito.

No contexto histórico atual do Brasil, após um acordo nacional de Estado com as estruturas parlamentares, jurídicas e midiáticas, onde se consolida um impedimento de uma presidência tendo bases tão questionáveis e com um caráter tão fortemente marcado pela misoginia, se entravam muitas perspectivas, numa conjuntura que coloca o campo de debate em colapso. $\mathrm{O}$ avanço do conservadorismo e dos discursos de ódio, com intenso crescimento de ideologias de extrema direita, que primam por um Estado mínimo de direitos, montam um cenário de retrocessos onde o simples fato de discutir sobre políticas públicas de direitos humanos, voltadas para enfrentamento a violência contra minorias, tornou-se um desafio ainda maior.

Com isso, por meio do Estatuto da Juventude (BRASIL, 2013a), este texto propõe uma análise crítica e reflexiva sobre a garantia de direitos humanos, por meio de políticas públicas voltadas para o enfrentamento às violências motivadas por gênero, sexualidade, raça, etnia e classe, perpetradas contra jovens no Brasil.

\section{JUVENTUDES, VIOLÊNCIAS E POLÍTICAS PÚBLI- CAS: CAMINHOS QUE SE CRUZAM}

"O Brasil possui cerca de 50 milhões de jovens, com idade entre 15 e 29 anos" (BRASIL, 2013b, p. 5). De modo oposto a esse alto quantitativo populacional, ainda é frágil a compreensão frente à necessidade e a importância das políticas públicas para garantia de direitos para a juventude, de modo que "é recente a inclusão desta temática na agenda política do Brasil e do mundo" (BRASIL, 2006, p. 6).

No domínio brasileiro, as demandas juvenis ganharam força com a criação da Política Nacional da 
Juventude (PNJ) em 2003, a qual estabeleceu em 2005, a criação da Secretaria Nacional da Juventude (BRASIL, 2013b). Com isso, emergiram paulatinamente experiências inéditas voltadas à inserção dos direitos humanos por meio de Políticas Públicas (PP), potencializando uma série de ações integradas entre todas as instâncias estatais.

“Esse processo foi desencadeado por motivos emergenciais, já que os jovens são os mais atingidos pelas transformações no mundo do trabalho e pelas distintas formas de violência que caracterizam o século XXI" (BRASIL, 2013b, p. 6). Nessa conjuntura, as três Conferências Nacionais da Juventude contribuíram para o aprofundamento e amadurecimento de uma política pública em todo território nacional. Observa-se que por meio de diversos atores sociais, foram discutidas quais as ações prioritárias poderiam ser desenvolvidas em defesa deste segmento.

Desde a primeira Conferência em 2008, considerando as políticas da juventude como transversais, uma soma de demandas sociais foi constatada, de modo que numa síntese da última conferência em 2015, em consonância com o Capítulo II do Estatuto da Juventude, foram destacados 11 eixos temáticos. Como resultado metodológico, foi elaborado um conjunto de propostas que serviram como subsídio para o Plano Nacional de Juventude.

A distribuição de propostas por eixos temáticos foi sistematizada na seguinte divisão: Participação, 35 propostas; Educação, 37 propostas; Trabalho, 40 propostas; Diversidade, 40 propostas; Saúde, 47 propostas; Cultura, 30 propostas; Comunicação, 26 propostas; Esporte, 26 propostas; Território e mobilidade, 29 propostas; Meio ambiente, 44 propostas; Segurança, 31 propostas; totalizando entre os 11 eixos, 385 propostas.

Especificamente sobre o eixo da diversidade, as 40 propostas foram destacadas na direção de aprovar a Lei que define os crimes de ódio e de intolerância e as formas de coibi-los, nos parâmetros de outras Leis, tal como a de crime de racismo, para proteger todas as pessoas, inclusive jovens, independente de classe e origem social, condição de migrante, refugiado ou deslocado interno, orientação sexual, identidade e expressão de gê- nero, idade, religião, situação de rua e deficiência. Mas, infelizmente, lançando olhar ao paradigma da violência na juventude, este Plano Nacional parece estar muito longe de ser legível como uma pauta de prioridade entre os estados e municípios brasileiros.

A condição vislumbrada é altamente preocupante. O Mapa da Violência de 2014, desenvolvido subsequente ao Estatuto da Juventude, já assinalava a importância dessa questão, por meio da sua publicação Os Jovens do Brasil (WISELFISZ, 2014). Além de dedicar um capítulo para discorrer sobre a transformação do conceito de juventude trazido com o Estatuto, esse documento já alertava sobre a dimensão racial como fator de vitimização juvenil, já que $77 \%$ dos jovens mortos por homicídio, eram registrados como negros ou pardos (WISELFISZ, 2014).

Nessa época, os maiores índices de mortalidade violenta, já se configuravam entre 15 e 29 anos (WISELFISZ, 2014). Ademais, no recorte de idade de 16 e 17 anos no Brasil, num percurso do ano de 1980 até 2015, houve um acréscimo de 9,7\% nas taxas de jovens envolvidos em acidentes de transporte; um aumento de $15,4 \%$ no número de suicídios e nessa mesma lógica, a participação dos jovens em homicídios passa de $9,7 \%$ para $46 \%$, representando um crescimento de 372,9\% (WISELFISZ, 2015).

Em suma, como se constata desde o primeiro Mapa da Violência, divulgado no ano de 1998, a principal vítima da violência homicida no Brasil continua sendo a juventude, de modo que os dados recentemente publicados demonstram que na faixa de 15 a 29 anos de idade, o crescimento da letalidade violenta continua sendo bem mais intenso do que no resto da população (WISELFISZ, 2016). Nesta análise, nota-se que as violências relacionadas a crimes estão majoritariamente associadas ao público juvenil negro, pobre e morador de comunidades mais segregadas, onde é incipiente a presença do Estado por meio de equipamentos públicos e bens culturais.

De maneira semelhante, as mulheres jovens negras, são as mais atingidas por situações de violência doméstica e intrafamiliar. Na mesma lógica, os dados do Relatório de Violência Homofóbica no Brasil, 
elaborado em 2013 e publicado e 2016, demonstram que a população Lésbicas, Gays, Bissexuais, Travestis, Transexuais e Transgêneros (LGBT) que mais é acometida por violações são os jovens entre 18 e 24 anos (BRASIL, 2016). Também a juventude indígena é vítima do descaso, ocupando último lugar na escala social, chegando a apresentar entre o povo jovem, um índice de suicídio que chega a seis vezes mais que o restante da média do Brasil (RUFFATO, 2016).

Para sanar essas condições de desigualdade que se relacionam de forma interseccional, as políticas públicas têm o papel fundamental de garantir mecanismos adequados de suporte para que os jovens possam desenvolver sua formação, processar suas buscas, construir seus projetos e percursos de inserção na vida social. Mas para dar conta da pluralidade de dimensões da vivência juvenil, é necessário ações de políticas transversais, que envolvam educação, trabalho, saúde, cultura, esporte e lazer, tal como foi sugerido nas conferências acima mencionadas. Entretanto, a caminhada é muito complexa, permeada de desafios, desigualdades, opressões e diferenças que marcam as experiências de cada sujeito e que nem sempre são devidamente respeitadas.

Desta forma, é prioridade pensar em políticas públicas que focalizem tais vulnerabilidades e promovam mudanças, conforme os estudos de Vázquez e Delaplace (2004, p. 1), as políticas públicas "resolvem um problema público de forma racional através de um processo de ações governamentais”. E, com isso almejando o fortalecimento da relação entre Estado e sociedade com a juventude.

Por se afirmar que a juventude é vivida de diferentes formas, faz-se necessário perceber como essa diversidade de experiências assimétricas afeta o cotidiano desses jovens no acesso a oportunidades e aos seus direitos de acordo com sua renda familiar, gênero, raça, orientação sexual, local de moradia, ter ou não deficiência ou ser de comunidades étnicas/tradicionais. Com isso, como nenhuma categoria social existe no isolamento, mas sim em relação com outras categorias (MCCLINTOCK, 2010), a próxima sessão irá se desdobrar sobre a interseccionalidade entre gênero, sexuali- dade, raça, etnia e classe, adentrando no contexto dessas relações, por meio do Estatuto da Juventude.

\section{GARANTIA DE DIREITOS HUMANOS E INTER- SECCIONALIDADES ENTRE GÊNERO, SEXUALIDA- DE, RAÇA, ETNIA E CLASSE}

"Recentes reflexões acerca da produção da diferença e da análise da desigualdade social vêm investindo na articulação dos chamados 'marcadores sociais da diferença”' (MOUTINHO, 2014, p. 203). Nesse leque de possibilidades, pensar na necessidade de explorar a intersecção entre as dimensões de gênero, sexualidade, raça, etnia, classe e quaisquer outras diferenciações sociais relevantes, tem ganhado destaque.

A interseccionalidade, debate fortemente influenciado pelas feministas negras norte-americanas (MOUTINHO, 2014), segundo Crenshaw (2002), traz a conceituação do problema que busca capturar as consequências estruturais e dinâmicas da interação entre dois ou mais eixos de subordinação, referindose à forma pela qual ações e políticas específicas geram opressões e sistemas discriminatórios que criam desigualdades básicas. Como não se pode separar a categoria gênero das relações políticas, econômicas, sociais, culturais e raciais (SOUZA; RATTS, 2008), muitos estudos passam a incorporar as possíveis intersecções entre diversas categorias de diferenciação.

Conforme Crenshaw (2002) essa associação entre sistemas múltiplos de subordinação tem sido descrita de vários modos, tais como: discriminação composta, cargas múltiplas, dupla ou tripla discriminação. Esse reconhecimento crescente de que as relações políticas (isto é, relações desiguais de poder) estão implicadas nas teorias do conhecimento, ganha uma centralidade necessária em análises mais recentes, que consideram fundamental explorar "outras" categorias de diferenciação social como "marcas" a serem contempladas na análise de contextos específicos (PISCITELLI, 1996). Porém, como a autora citada corrobora, a questão não 
se resolve simplesmente adicionando as diversas formas de opressão na configuração da condição social das relações, mas sim, percebendo a interconexão entre as desigualdades.

Na década de 2000, a articulação entre diferentes categorias e interseccionalidades, estavam amplamente difundidas, formuladas no plano teórico por meio de leituras críticas e coincidindo com intensas reivindicações, relativas à questão da diferença (PISCITELLI, 2008). Todavia, ao passo em que este debate se insere no plano acadêmico, ainda é principiante a sua representação nos aparatos legais.

Ao analisar como se dá essa inter-relação nas experiências de ser jovem, conforme os dados estatísticos citados anteriormente, percebe-se que gênero, sexualidade, raça, etnia e classe estão historicamente listados como alvos mais vulneráveis às experiências interseccionais. Com base nisso, como essa realidade é representada no Estatuto da Juventude?

Primeiramente verifica-se que embora haja uma seção do referido documento, intitulada "Do direito à Diversidade e à Igualdade” (BRASIL, 2013a), que adota na sua centralidade aspectos de gênero, sexualidade, raça, etnia e classe, é necessário ponderar que todas as demais seções, trazem no seu conteúdo questões nevrálgicas para a garantia de direitos humanos e para a efetivação de políticas públicas de combate a violência nessas diferentes intersecções.

0 Estatuto da Juventude, que estruturalmente está disposto ao longo de 48 páginas, estando dividido em 2 subtítulos, 3 capítulos, 11 seções e 48 artigos, aborda direitos e políticas públicas direcionadas a cidadania, participação social e política, representação juvenil, educação, profissionalização, trabalho e renda, diversidade e igualdade, saúde, cultura, comunicação, liberdade de expressão, desporto e lazer, mobilidade, sustentabilidade, segurança pública e acesso à justiça (BRASIL, 2013a).

Dentre os temas abordados, especialmente na sessão de número 9, "Do direito à Diversidade e à Igualdade", é possível incorporar uma análise do texto documental no viés da interseccionalidade. A pauta das diferenças aparece como prioridade para combater a omissão do poder público em relação às experimentações das juventudes, para garantir a perenidade das políticas públicas e da sua implementação nos municípios, tendo como objetivo que os jovens tenham os instrumentos legais e financeiros necessários para o seu desenvolvimento integral.

A sessão ressalta a igualdade de direitos e oportunidades, descrevendo que nenhum jovem pode ser discriminado por questões da sua raça, etnia, gênero, classe, cultura, origem, sexo, orientação sexual, deficiência, religião. Ainda contempla o que cabe ao poder público federal, estadual, municipal e distrito federal para assegurar tais prerrogativas. Apesar disso, e não é um fato pontual nem isolado, ainda é perceptível um cenário de violações e de um verdadeiro "massacre" a população juvenil. Como citado no corpo do trabalho, não só dados do Mapa da Violência, como também a mídia, destacam cotidianamente cenas de violência e injustiças fomentadas pela discriminação por raça, etnia, por gênero, sexualidade e por classe, as quais estão longe de garantir oportunidades mais igualitárias, na contramão do direito a diversidade e a igualdade, destacado no Estatuto da Juventude.

Nesse sentido, embora o eixo 9 do documento, por meio da menção às diferenças de raça, etnia, gênero, sexualidade e classe, se aproxime de uma lógica analítica interseccional, nota-se que não há um aprofundamento concreto sobre como os marcadores sociais se interligam entre si. Ou seja, as categorias de desigualdade são tratadas de forma isoladas e fragmentadas, assim não atinge um nível de compreensão sobre a gama de violências que se agravam nas interconexões. Se esse entendimento não é amplo na forma do documento, na atuação prática a garantia de direitos reflete um desafio onde a interseccionalidade parece se distanciar ainda mais, tal como evidenciam os dados sobre violência anteriormente elencados, no qual as maiores vítimas carregam tantos preconceitos da sociedade.

Concomitante a este processo, o povo brasileiro vivencia um cenário regressivo assumido pela agenda neoliberal, que põem em curso um amplo programa de ataque não somente aos direitos da juventude, como modifica profundamente toda estrutura social 
que balizava a Constituição Federal de 1988. Entre as principais medidas que se encontram incluídas nessa conjuntura de retirada de direitos dos jovens, destaca-se a recente reforma da educação, alterando todo o sistema do ensino médio público. Diminuindo disciplinas, comprimindo áreas do conhecimento, aumentando a carga horária, colocando como facultativo a qualificação de magistrado na docência, essa nova legislação (BRASIL, 2017), altera o currículo, priorizando o ensino técnico e se voltando a exigência do capital, intensificando a projeção dos jovens periféricos a situações de vulnerabilidade social.

Nessa direção, ainda há o agravante da Emenda Constitucional do Teto de Gastos 95/2016 que congela os gastos primários por 20 anos; a proposta de reforma da previdência que se aprovada, praticamente interdita a possibilidade dos setores mais pobres de acessarem os benefícios previdenciários; a aprovada reforma trabalhista e a nova Lei que permite terceirizar todas as atividades laborais, intensificam os níveis de exploração do trabalho e combinada com as outras medidas constituem um desmonte violento das políticas públicas e dos direitos sociais no Brasil.

0 que se denota é que está em curso um alinhamento político conservador que a cada dia ganha mais adeptos e simpatizantes. Discursos de ódio social alimentam o cerceamento da pobreza, da questão de gênero, sexualidade, raça/etnia, das liberdades políticas e religiosas que criam contornos dramáticos para a situação brasileira, em especial a população juvenil. Soluções violentas e antidemocráticas são cada vez mais acentuadas. Propostas e práticas de criminalização aos movimentos sociais são constantes. Aparecendo de forma cada vez mais intensa, a repressão contra as manifestações políticas, protagonizadas por lideranças de extrema-direita que reproduzem discursos de ódio, ganham cada vez mais notoriedade.

A situação atual é a cada dia mais preocupante, na contramão de todas as prerrogativas das lutas sociais até então conquistadas e que vinham, mesmo que gradativamente, garantindo minimamente a garantia e efetivação de direitos. Com este cenário, pode-se dizer que as questões da diferença precisam estar no centro de muitas discussões contemporâneas, como em especial para as demandas interseccionais à juventude.

\section{CONCLUSÃO}

Pode-se concluir que as políticas públicas na perspectiva dos direitos humanos estão em um campo que ainda está em construção (VÁZQUEZ; DELAPLACE, 2004). É possível considerar que em um modelo de economia capitalista, que abarca um processo de globalização sistêmica (SILVEIRA, 2007), mesmo com a Constituição Federal (BRASIL, 1988) e com o Brasil sendo "parte de quase todas as convenções e tratados de direitos humanos celebrados no âmbito das Nações Unidas" (MAIA, 2007, p. 88) para estipular dispositivos que amparem os direitos das minorias, se por um lado representaram avanços, por outro evidenciam um somatório de falhas no que se refere a sua efetivação, na qual o Estado se apresenta como hegemônico e contraditório, a violência e a violação de direitos continuam acontecendo.

Ao observar a trajetória do Estatuto da Juventude e sua interconexão com as políticas públicas de direitos humanos, focadas para intersecção entre violências de gênero, sexualidade, raça, etnia e classe, embora seja perceptível uma construção legal na tentativa de dilatar os espaços de atendimento, demais ações inclusivas e transversais, visando não só o enfrentamento como a prevenção em rede, é necessário salientar que entre a existência dos documentos até a sua efetivação há um longo e distante caminho. Como explica Bobbio (1992, p. 10), “uma coisa é proclamar um direito, outra é desfrutá-lo efetivamente”.

Constata-se que o Estatuto está bem fundamentado no campo do discurso e na construção textual, entretanto, ainda não atinge um ideal de horizontalidade entre o público alvo e os gestores da política, havendo uma hierarquia que funciona no distanciamento e na fragmentação da efetivação dos direitos. Imerso num processo de democracia representativa, ainda há uma hierarquia para constituição das suas Conferências, na qual a sociedade acaba não sendo amplamente consul- 
tada e a população jovem evidencia um peso muito inferior para a tomada de decisão, se comparado àquele exercido pelo governo, órgãos e ministérios.

No decorrer dos anos, percebendo-se um número crescente de participantes na construção dessas políticas, tendo aumentado o espaço para participação popular, por meio, por exemplo, da internet, essas iniciativas ainda precisam ser pensadas em moldes que realmente se ancorem coletivamente. É necessário se pensar em mecanismos que viabilizem de fato uma maior participação e tomada de decisão da juventude, evitando que os jovens, via de regra, sejam apenas massa de manobra dos governos e manipulados por quem ocupa cargos para legitimar as políticas “ditas para” a juventude.

Conclui-se ainda que o contexto político atual regressivo abrange duas frentes que afetam diretamente a população juvenil: de um lado, trata-se de uma grande ofensiva do capital contra o trabalho, materializada nas contras-reformas em curso no país e da destruição das garantias democráticas (especialmente por meio da Reforma do Ensino médio; da diminuição da Maioridade Penal, que tem seu debate cada vez mais latente; da Emenda Constitucional do Teto de Gastos; da Reforma da Previdência; da Reforma Trabalhista; de um amplo processo de privatizações e terceirizações; da criminalização dos movimentos e lutas sociais); em outra frente, verifica-se o avanço assustador de uma ofensiva moral, religiosa e cultural, de extrema-direita, reforçando ataques as minorias sociais, em especial nas relações de raça/etnia, sexualidade, gênero e classe.

Esta realidade impacta acerca das intersecções de igualdade de oportunidades, de modo que o próprio Estado criminaliza os jovens de modo interseccional. Esse conjunto de fatores reflete nas experiências vivenciadas pela juventude, que anseia ultrapassar as fronteiras que hoje estão impostas nos diversos ambientes da sociedade. Afinal, não são os jovens que são violentos, eles apenas denunciam sua condição de segregação e invisibilidade, atuando como reflexo de uma dimensão de violência e opressão social do próprio sistema onde estão inseridos.
Eu vou à luta com essa juventude Que não corre da raia a troco de nada

Eu vou no bloco dessa mocidade

Que não tá na saudade e constrói

A manhã desejada.

(E vamos a luta - GONZAGUINHA).

\section{REFERÊNCIAS}

AMORIM, R.H.P. O jovem, o estatuto da juventude e a EC 65/2010. Âmbito Jurídico, Rio Grande, XIV, n.93, out. 2011. Disponível em: <http://www. ambito-juridico.com.br/site/?n_link=revista_artigos_ leitura\&artigo_id=10545>. Acesso em: 24 mar. 2017.

BOBBIO, N. A era dos direitos. Rio de Janeiro: Campus, 1992.

\section{BRASIL. Constituição da República Federativa do}

Brasil. Brasília: Presidência da República, 1988.

\section{BRASIL. Estatuto da Criança e do Adolescente.}

Brasília: Presidência da República, 1990. Disponível em: <http://www.planalto.gov.br/ccivil_03/leis/ L8069.htm>. Acesso em: 17 mar. 2017.

BRASIL. Estatuto do Idoso. Brasília: Presidência da República, 2003. Disponível em: <http://www. planalto.gov.br/ccivil_03/leis/2003/L10.741.htm>. Acesso em: 17 mar. 2017.

\section{BRASIL. Guia de políticas públicas de juventude.}

Brasília: Secretaria Nacional de Juventude, 2006. Disponível em: <http://www.crianca.mppr.mp.br/ arquivos/File/publi/seed_pr/guia_de_politicas_ publicas_br.pdf>. Acesso em: 17 mar. 2017.

BRASIL. Estatuto da Juventude. Brasília: Presidência da República, 2013a. Disponível em: <http://www. planalto.gov.br/CCIVIL_03/_Ato2011-2014/2013/ Lei/L12852.htm>. Acesso em: 17 mar. 2017.

BRASIL. Políticas públicas de juventude. Brasília: Secretaria Nacional de Juventude, 2013b. Disponível 
em: <https://www.bemtv.org.br/centralsolidaria/ downloads/cartilha_politicas_publicas_para_ juventude_2013.pdf>. Acesso em: 17 mar. 2017.

\section{BRASIL. Relatório sobre violência homofóbica}

no Brasil: ano de 2013. Brasília: Secretaria de Direitos Humanos, 2016. Disponível em: <http:// www.sdh.gov.br/assuntos/lgbt/dados-estatisticos/ Relatorio2013.pdf>. Acesso em: 28 set. 2016.

BRASIL. Lei $\mathbf{n}^{\mathbf{0}} \mathbf{1 3 . 1 4 1 5}$ de 16 de fevereiro de 2017. Brasília: Secretaria da Presidência da República, 2017. Disponivel em: <http://legis.senado.leg.br/legislacao/ ListaTextolntegral.action?id=251273\&norma $=270661$. Acesso em: 24 mar. 2017.

MAIA, L.M. Educação em direitos humanos e tratados internacionais de direitos humanos. In: SILVEIRA, R.M.G. et al. Educação em direitos humanos: fundamentos teórico-metodológicos. João Pessoa: Universitária, 2007.

MCCLINTOCK, A. Couro Imperial: raça, sexualidade e gênero no embate colonial. Campinas: Unicamp, 2010. Disponível em: <http://www.ifch.unicamp. br/ojs/index.php/rhs/article/viewFile/1217/848>. Acesso em: 18 jul. 2015.

MOUTINHO, L. Diferenças e desigualdades negociadas: raça, sexualidade e gênero em produções acadêmicas recentes. Cad. Pagu, Campinas, n.42, Jun. 2014. Disponível em: <http://www.scielo.br/pdf/cpa/n42/0104-8333cpa-42-00201.pdf>. Acesso em: 18 jul. 2015.

PISCITELLI, Adriana. "Sexo Tropical”: Comentários sobre gênero e "raça" em alguns textos da mídia brasileira. Revista Estudos Feministas, Florianópolis, UFSC, v.6/7, p.9-35, 1996. Disponível em: <http:// periodicos.bc.unicamp.br/ojs/index.php/cadpagu/ article/view/1859>. Acesso em: 18 jul. 2015.
PISCITELLI, Adriana. Interseccionalidades, categorias de articulação e experiências de migrantes brasileiras. Sociedade e Cultura, v.11, n.2, p.263-274, 2008. Disponível em: <http://www. revistas.ufg.br/index.php/fchf/article/view/5247>. Acesso em: 19 jul. 2015.

RUFFATO, L. Os índios, nossos mortos. El País, 13 jul. 2016. Disponível em: <http://brasil.elpais.com/ brasil/2016/07/13/actualidad/1468422915_764996. html>. Acesso em: 3 jun. 2017.

\section{SILVEIRA, R.M.G. et al. Educação em direitos}

humanos: fundamentos teórico-metodológicos. João Pessoa: Universitária, 2007.

\section{SILVEIRA, R.M.G. Educação em/para os}

direitos humanos: entre a universalidade e as particularidades, uma perspectiva histórica. In: SILVEIRA, R.M.G. et al. Educação em direitos humanos: fundamentos teórico-metodológicos. João Pessoa: Universitária, 2007.

SOUZA, L.F.; RATTS, A. Raça e gênero sob uma perspectiva geográfica: espaço e representação.

Boletim Goiano de Geografia, v.28, n.1, jan-jun. 2008, p.143-156. Disponível em: <http://www. revistas.ufg.br/index.php/bgg/article/view/4907>. Acesso em: 19 jul. 2015.

VÁZQUEZ, D.; DELAPLACE, D. Políticas públicas na perspectiva de direitos humanos: um campo em construção. Revista Internacional de Direitos Humanos, v.1, n.1, p.25-66, jan. 2004. Disponível em: <http://www.egov.ufsc.br/portal/conteudo/políticaspúblicas-na-perspectiva-de-direitos-humanos-umcampo-em-construção>. Acesso em: 8 fev. 2015.

\section{WISELFISZ, J.J. Mapa da Violência 2014. Os Jovens} do Brasil. Brasília: Presidência da República, 2014. Disponível em: <http://www.mapadaviolencia.org.br/ pdf2014/Mapa2014_JovensBrasil.pdf>.

Acesso em: 21 mar. 2017. 
WISELFISZ, J.J. Mapa da Violência 2015.

Adolescentes de 16 e 17 anos no Brasil. Rio

de Janeiro: Faculdade Latino-Americana de

Ciências Sociais (FLACSO), 2015. Disponível em:

<http://www.mapadaviolencia.org.br/pdf2015/

mapaViolencia2015_adolescentes.pdf>

Acesso em: 21 mar. 2017.
WISELFISZ, J.J. Mapa da Violência 2016. Homicídio por armas de fogo no Brasil. Rio de Janeiro: Faculdade Latino-Americana de Ciências Sociais (FLACSO), 2016. Disponível em: <http://www. mapadaviolencia.org.br/pdf2016/Mapa2016_armas_ web.pdf>. Acesso em: 21 mar. 2017. da região de Chapecó - UNOCHAPECó; Mestre em Direitos Humanos, Cidadania e Políticas Públicas pela Universidade Federal da Paraíba UFPB; Mestranda e bolsista CNPq no Programa de Pós-Graduação em Sociologia pela Universidade Federal da Paraíba - UFPB. E-mail: juciane.psicologia@gmail.com

2 Graduada em Serviço Social pela Pontifícia Universidade Católica do Rio Grande do Sul - PUCRS; Especialista em Educação, Sexualidade e Relações de Gênero pela Universidade Federal do Rio Grande do Sul UFRGS; Mestre em Serviço Social pela Universidade Federal da Paraíba - UFPB; Professora junto a Escola de Conselhos de Direitos e Tutelares do Estado da Paraíba-PB. E-mail: claudiaveronese1973@gmail.com 
